\title{
Regional effects of university funding: Excellence at the cost of regional disparity?
}

\author{
Johannes Koenig1 • Thomas Brenner ${ }^{2}$ Guido Buenstorf ${ }^{1,3,4} \mathbb{D}$
}

Accepted: 18 August 2017 / Published online: 5 September 2017

(C) The Author(s) 2017. This article is an open access publication.

\begin{abstract}
We investigate regional repercussions of the recent shift toward focusing academic excellence in German science policy. We find that the regional concentration of merit-based public research funding has increased since the late 1990s. However, it is challenging to identify the characteristics of winning and losing regions. There is some evidence indicative of advantages for regions with larger overall university size. In contrast, our results do not suggest that more urbanized regions, or regions with stronger private-sector $\mathrm{R} \& \mathrm{D}$ activity, benefit disproportionately from the policy shift.
\end{abstract}

Keywords Science policy $\cdot$ Regional effects $\cdot$ Exzellenzinitiative

\section{Introduction}

In January 2016 a panel of high-ranked international experts led by the Swiss physicist and research manager Dieter Imboden published a critical review (Imboden et al. 2016) of the German Exzellenzinitiative ("initiative for excellence"). Established in 2006, the Exzellenzinitiative constituted a watershed in the public funding of Ger-

G. Buenstorf

buenstorf@uni-kassel.de

1 Institute of Economics and INCHER-Kassel, University of Kassel, Moenchebergstrasse 17, 34109 Kassel, Germany

2 Section Economic Geography and Location Research, Philipps University Marburg, Marburg, Germany

3 IWH Leibniz Institute of Economics, Halle, Germany

4 Institute of Innovation \& Entrepreneurship, University of Gothenburg, Göteborg, Sweden 
man universities. To a hitherto unseen extent, funds were allocated on the basis of academic merit, with the explicit objective of increasing the international research competitiveness of the best German universities. In contrast, only minimal attention was paid to concerns of balancing the flow of money between the individual federal states and universities, or other considerations of regional or institutional equity (Kehm 2006). In its recommendation for a successor program, the Imboden commission wholeheartedly endorsed this exclusive focus on the pursuit of academic excellence. Policy makers were admonished that the goals of world-class research and international competitiveness "should not be watered down by mixing them up with other goals, however worthy and pressing they may be" (Imboden et al. 2016, p. 6). The commission even proposed to further narrow down the scope of the program and to discontinue the funding of graduate schools that have been part of the Exzellenzinitiative.

The Exzellenzinitiative was part of a broader regime shift in the prerogatives of German science policy de-emphasizing universities' roles in fostering regional innovation and development activities. This regime shift was and is highly controversial (cf., e. g., Münch 2006; Hartmann 2010; Vogt 2014; Arzt et al. 2016) but its regional implications have not received much attention in the debate. ${ }^{1}$ This apparent lack of interest is surprising because the regional impact of universities has been discussed comprehensively. A sizeable literature has focused on the contributions that universities make to regional economic development (e. g., Fritsch et al. 2007; Astebro and Bazzazian 2011) as part of fulfilling their "third mission" of commercializing results (Etzkowitz and Leydesdorff 2000) and engaging with non-academic partners (Perkmann et al. 2013). This literature suggests that universities matter for their home regions beyond teaching, research, employment and multiplier effects. Frequently the regional relevance of universities is reflected in their strategies (Belenzon and Schankerman 2013). The available theoretical and empirical work indicates that the increased focus on academic excellence may not be neutral from a regional perspective. It may alter the regional distribution of university funding, which may in turn compromise the ability of the losing universities to contribute to innovation and the development of their host regions. Accordingly, changing the distribution of funding among universities can be expected to impact on the regional distribution of economic activity.

In this paper we investigate the regional repercussions of the recent shift toward academic excellence in German science policy. Specifically, we trace how the regional concentration in universities' merit-based research funding (measured by Deutsche Forschungsgemeinschaft (DFG) funds, which include Exzellenzinitiative funding after 2005) evolved over time. We also begin to identify factors that help account for which regions are among the winners and losers of the recent regime shift. We find that the already pronounced inequality of DFG research funding increased further in the years following the policy shift, which is consistent with concerns about potentially adverse regional repercussions. Regions with larger overall university size benefit more than proportionately from merit-based DFG funding,

\footnotetext{
1 An explorative paper by Blume and Postlep (2009), and the discussion of descriptive patterns in a report of Deutsche Forschungsgemeinschaft (DFG 2015) are notable exceptions.
} 
and there is some evidence suggesting that this advantage became stronger after the regime change. In contrast, our results do not suggest that more urbanized regions, or regions with stronger private-sector $\mathrm{R} \& \mathrm{D}$ activity, benefit disproportionately from the policy shift.

The remainder of the paper is structured as follows. Sect. 2 provides some theoretical background about the recent shift in university funding in Germany as well as the relevance of disparities in research funding. Data and empirical methods are introduced in Sect. 3. We report the results of the empirical analysis in Sect. 4 and conclude in Sect. 5.

\section{Theoretical background}

\subsection{Recent shifts in university funding in Germany}

Similar to other Western countries, (West) Germany experienced a wave of founding events of new universities in the 1960s-70s. The establishment of new universities was part of a large-scale expansion of higher education motivated by expected future shortages of highly skilled workers (Picht 1964; Ellwein 1985). At the same time, the newly established universities had a regional development mission to accomplish. They were mostly located in disadvantaged regions facing economic hardships due to their geographic location (e.g., Kassel, which was situated close to the border to socialist East Germany), sparsely settled regional environment (e. g., Regensburg in eastern Bavaria) and/or challenges from structural change in declining industrial centers (e.g., Bochum and Duisburg in the Ruhr area, but also Augsburg or Wuppertal). Policy makers were quite explicit about their hopes that the new universities would help boost the economic development of the surrounding regions.

Following another wave of restructuring and establishment of new universities after German reunification (Mayntz 1994), the structure of funds for the German universities (almost all of which are public) has substantially changed in the past decades. Between 1995 and 2010, the share of third-party funds (also known as program funding), relative to institutional funding (block grants) and universities' own income, increased by about $70 \%$ (from 8.4 to $14.3 \%$; Destatis 2013) 2 $^{2}$ Similarly, between 1995 and 2010 the share of third-party funds among the research expenditures of German universities jumped from 29 to 47\% (Winterhager 2015). This shift is significant because institutional and third-party funds follow different rationales. Institutional funding is primarily allocated according to the educational services that a university provides. It varies strongly with the number of enrolled students, and differences across universities of similar size and disciplinary profile tend to be relatively minor. In contrast, third-party funding is provided by public or private bodies for specific activities in research, teaching or training of junior researchers and mostly on a competitive basis. ${ }^{3}$ Its allocation to individual universi-

\footnotetext{
2 It further increased to $14.9 \%$ in 2014 (Destatis 2016).

3 Quantitatively, the DFG was most important source of third-party funding in Germany in 2012-2014 (Destatis 2016).
} 
ties is highly contingent on the universities' research profiles, as well as their past research performance and reputation. As a consequence, third-party funds may be distributed more unevenly across universities and, by extension, regions.

In parallel with the increased role of third-party funds, Germany has witnessed an increasing focus on academic excellence in the allocation of public funds for university research. Compared to countries such as the U.S. or the U. K., German universities have historically been relatively homogenous in terms of educational offerings, student body composition, research quality and institutional reputation (Hüther and Krücken 2016). Outright competition between schools was eschewed, as concentration of research prowess at individual schools was considered an undesirable hazard to the constitutional principle of equalizing the standards of living across German regions. (The same principle had also provided an impetus for starting new universities in the 1960s-1970s, as discussed above).

All this began to change in the late 1990s when policy makers increasingly focused on the competitive character of public research. The starting point of this change is typically attributed to the BioRegio contest launched by the Federal Ministry of Education and Research (BMBF) in 1997 (Eickelpasch and Fritsch 2005; Dohse 2007). BioRegio's objective was to enhance the global competitiveness of the German biotechnology research and industry. Regional collaborative projects with partners from universities, non-university public research organizations (PROs) and industry were eligible for funding, and the best proposals were selected by an international jury. Later BMBF programs used a similar basic design.

Subsequently the same approach of further strengthening the already leading players was also adopted in university funding (Kehm 2006). This shift is epitomized by the Exzellenzinitiative, a joint initiative by the Federal government and the Länder in which about $€ 4.6$ billion of additional funding (about $4 \%$ of the overall research funding of German universities) were provided over the twelveyear period from 2006 to 2017 (Imboden et al. 2016). Even though the Exzellenzinitiative eventually turned out to be less radical than initial plans to establish a few "elite universities" in Germany, the funding it provided was still highly "chunky". Three lines of support were distinguished: integrated university-level development concepts (Zukunftskonzepte), clusters of excellence and graduate schools. It is noteworthy that the winning universities were unevenly distributed in space. Among the 14 schools with supported development concepts, five were located in southern Baden-Wuerttemberg, two each in neighboring Bavaria, in Berlin and in NorthRhine Westphalia; as well as one each in Bremen, Lower Saxony and Saxony. Aggregating all lines of funding, individual funding per (successful) university varied from less than $€ 10$ million to more than $€ 350$ million (DFG 2015). Additional funds could amount to as much as $14 \%$ of the overall budget of successful schools (Imboden et al. 2016).

The Exzellenzinitiative is only the most extreme and most visible example of a broader shift toward large-scale merit-based funding. Further adding to the potential of regional disparities is the DFG's increasing focus on large-scale programs such as Sonderforschungsbereiche, research groups and graduate schools, while funding of smaller projects that individual researchers can apply for has lost in 
relative importance. ${ }^{4}$ Individual Länder such as Hessen and Saxony have moreover emulated the Exzellenzinitiative in smaller-scale regional programs.

\subsection{Why are the regional effects of universities affected by disparities in research funding?}

It might be suspected that increasing regional disparities in university funding are a relevant concern only for researchers and managers of "losing" universities. However, a sizeable literature shows that universities tend to have substantial economic effects on their host regions (for a review cf., e. g., Drucker and Goldstein 2007). To the extent that these effects depend on the research prowess of the respective universities, more pronounced inequality and a shifting regional balance in research funding are likely to induce shifts in the economic development of the universities' home regions as well. The increased emphasis on excellence in the funding of German universities may then have substantial repercussions on regional economic disparities. In a long-term perspective, effects of the policy shift may be even stronger as public research and private-sector activities are mutually reinforcing through co-evolutionary processes at the regional level (Blankenberg and Buenstorf 2016). Multiple potential conduits of the economic effects of universities have been identified, and a rich empirical literature has explored these pathways. In the following, we briefly discuss the most important conduits, as well as how they may be affected by shifts in universities' research funding.

When the German university system was expanded in the 1960s/1970s, both "demand side" and "supply side" effects on universities' home regions were expected. "Demand side effects" derive from the regional expenditures made by the university, its employees and students, as well as from multiplier effects. A number of regional case studies have explored the relevance of demand-side effects. They typically report effects of substantial magnitudes (cf., e. g., Beckenbach et al. 2011). It is less clear to what extent demand-side effects depend on the research funding of the respective university. At least in the short run universities' research activities probably generate less regional demand than teaching, which brings consuming students to the region. Long-run effects of research may be more pronounced and diverse, e. g., if better research (or higher reputation) helps universities attract more students and firms, including startups, to the university region.

The "supply-side" effects of universities are multifaceted. Traditionally, the focus of attention has been on the educational role of universities. To a substantial extent, the expansion of the German university system in the 1960s-70s was based on the objective to enhance the supply of human capital-taking the form of highly skilled university graduates - in the respective regions. Consistent with this expectation, Schubert and Kroll (2014) find that the supply of graduates is associated with higher regional growth. For a more detailed analysis of how relevant regional disparities

\footnotetext{
4 Funded Einzelanträge and Direkte Nachwuchsförderung accounted for $40.8 \%$ of DFG funding in the 2002-2004 period (DFG 2006). Their share diminished to 32.5\% in the 2008-2010 reporting period (DFG 2012). See also Potì and Reale (2007) for international evidence.
} 
in university funding are for the supply of human capital to the university's home region, the mobility of graduates has to be taken into account.

A rich literature has studied mobility decisions of graduates in various countries. Some idiosyncratic patterns have been observed. For instance, in the U.S. some Midwestern states are notorious for their loss of graduates to other, notably coastal, U.S. regions (Stephan 2012), whereas London is important as an "escalator" for graduates in the U. K. (Faggian and McCann 2009). In the German context, Buenstorf et al. (2016) show that economic as well as social factors affect the propensity of graduates to start work in their university regions. Universities located in larger cities tend to retain more graduates, who moreover exhibit a preference for regions that are similar to where they grew up in terms of culture and urbanity. A stylized fact in this literature is that those who studied outside their home regions are most likely to also move upon graduation. In turn, this suggests that attractive universities allowing students to study in their home region may also help increase the supply of human capital in that region, because if they study elsewhere they may be less likely to return home afterwards. Overall, in the sample of Buenstorf et al. (2016), about $43 \%$ of all graduates take up employment in the region where they graduated.

Much less is known about how strongly the choices of students depend on the research quality of universities. In the German case, university rankings have traditionally not played a big role in these choices, but this may change with the increasing public awareness of differences in institutional reputation. To the extent that there are (perceived) complementarities between research and teaching activities, universities that excel in research may be likely to attract more, and better, students. They will also provide better educated graduates to the respective region. This should be particularly relevant at the level of post-graduate studies. Based on these considerations, it seems plausible that increasing regional disparities in research funding may also increase regional disparities in the quantity and quality of university graduates. This effect will be stronger, the higher the mobility of incoming students and graduates, and the stronger the ties between research and teaching activities are.

In addition to university-related expenditures and the production of graduates, universities also affect their regional environment through the outcomes of their research activities, which suggests a direct channel through which changed prerogatives in research funding have repercussions at the regional level. This second type of "supply-side" effects has received increased attention in recent years. Following the seminal work by Jaffe (1989), numerous empirical studies have shown that universities' research activities spill over to private-sector innovation, and that these spillovers are more pronounced in the university region. Accordingly, industry R\&D may benefit from the co-location of university research. For the German context, Fritsch and Slavtchev (2007) find that such spillovers primarily emerge from highquality research. Their result is supported by research on the individual-level antecedents of researchers' interaction with private-sector partners. A wide range of 
studies finds that individual research productivity and knowledge transfer activities are complementary (e.g., Azoulay et al. 2009). ${ }^{5}$

\subsection{Who wins? Who loses? Potential determinants of imbalances in research funding}

The discussion in the previous subsection shows that there are multiple pathways through which differences in universities' research performance may have economic repercussions on the university region. Accordingly, increasingly pronounced regional imbalances in research funding, which likely give rise to increasingly pronounced imbalances in research output, may be of concern beyond the narrow interests of the affected researchers and university managers. How important these concerns are from a social welfare perspective depends not only on the extent of the regional imbalances, but also on the nature of winner and loser regions. In this subsection, we develop some hypotheses on the characteristics of regions that are likely to benefit or suffer from a shift towards merit-based research funding as has recently been observed in Germany.

To begin with, regions differ in the size of the university or universities located there. Larger universities find it easier to concentrate substantial funds on specific fields or disciplines, which may make it easier to finance large-scale equipment, engage in cutting-edge research in the respective specialization and to attract leading researchers. Among other factors contributing to scale economies, regions with larger university size are better able to offer matching positions to couples of toplevel researchers. Larger universities are also more likely to afford specialized staff helping them in their "grant seeking" (Schneider and Ji 1990) activities. In addition, having a larger pool of faculty in the field of specialization provides richer opportunities for mutually beneficial interaction, exchange, and networking, both within single universities and within the same university region. The importance of regional university size is further increased by the fact that, as noted above, largescale funding schemes have gained in importance over the past decades. Based on these considerations, we expect that "larger" university regions are better positioned in the competitive struggle for research funding, which leads to our first hypothesis:

Hypothesis 1: Regions that host universities of a larger (smaller) aggregate size benefit (suffer) from a shift toward competitive merit-based funding.

Universities differ not only in size but also in age, where age tends to be closely related to other differences. In the German context, a key distinction is that between traditional universities, such as Heidelberg and Göttingen, and the more recently established ones. The long history of their universities helps regions to build up reputation as research "hubs". Such reputation may not always correspond to cur-

\footnotetext{
5 Perkmann et al. (2013) suggest a more nuanced picture for the interaction of individual and organizational characteristics in conditioning engagement activities. They conjecture that engagement is often a resource mobilization strategy employed by high-performing researchers working at lower-ranked universities.
} 
rent research performance but will still be helpful in the competition for external resources. Consistent with this argument, Münch (2006) criticizes that traditional universities are overrepresented in decision-making bodies such as appropriations committees as well as in reviewer networks. Blume and Postlep (2009) similarly note that well-known names facilitate universities' fund raising efforts. These considerations imply that regions which can look back on a long university history will be in an advantageous position in competing for funds. We therefore predict:

Hypothesis 2: (Non-) traditional university regions benefit (suffer) from a shift toward competitive merit-based funding.

University regions' chances of securing merit-based funding depend not only on characteristics of their universities but also on those of the regions themselves. Available evidence suggests that university research benefits from the interaction with private-sector partners located in the same region (e. g., Blankenberg and Buenstorf 2016). This interaction may take a variety of forms ranging from private-sector sponsoring of university research to industry lobbying on behalf of regional universities. Universities located in larger regions are better positioned to find private-sector partners for mutually beneficial interaction. In addition, more urbanized regions tend to have richer and more diverse economic activities, which may foster creativity and innovation in the region (Jacobs 1961). Based on these considerations, it may be expected that larger regions tend to fare better in the competition for merit-based funding.

Hypothesis 3: Larger (smaller) university regions benefit (suffer) from a shift toward competitive merit-based funding.

Collaborative research with private-sector partners is an important channel through which the research activities of universities may benefit from interacting with their regional environment. Some funding agencies and programs require private-sector collaboration as a prerequisite for funding, and proximity to potential collaboration partners facilitates the identification of suitable matches. To the extent that university researchers learn and develop capabilities in collaborative research projects, such projects may also be beneficial for the acquisition of research funding (e. g., from the DFG) for which no private-sector partner is required. In this case, we would expect university regions with stronger private-sector R\&D capacities to have a competitive edge in the quest for merit-based funding. This leads to the following prediction:

Hypothesis 4: University regions with stronger (weaker) private-sector R\&D capacities benefit (suffer) from a shift toward competitive merit-based funding.

Finally, Germany's public research system is similar to that of other continental European countries such as France and Italy (but different from the Anglo-Saxon model) in that non-university public research organizations (PROs) play a strong role. Cutting-edge research is often conducted at Max Planck Institutes, whereas 
Helmholtz Centers are important as providers of large-scale research facilities. From a university perspective, PRO facilities are highly relevant collaboration partners in joint projects and in the training of junior researchers. Collaboration is facilitated by co-location, and whereas (due to the federalist funding of German public research) PRO facilities are spread throughout the country, they are not evenly distributed within the individual Länder. For instance, Max Planck facilities in Bavaria cluster in and around Munich (where the Max Planck headquarters are also located). These regional imbalances make it harder for university researchers in regions without such PRO facilities to find suitable partners for collaborative projects. This may be a relevant problem particularly for large-scale projects presupposing a minimum critical size to be competitive. The enhanced importance of such large-scale projects may add to the importance of being part of a larger regional "ecosystem" of research facilities. We therefore conjecture:

Hypothesis 5: University regions with larger (smaller) size of non-university public research activities benefit (suffer) from a shift toward competitive meritbased funding.

In the remainder of this paper, we will test Hypotheses 1-5 econometrically.

\section{Data and methods}

The 270 German labor market regions are adopted as geographic units of our empirical analysis. We use the classification of German labor market regions from the scheme for "improving regional economic structures", which is commonly used in regional research on Germany (see e. g. Brenner and Duschl 2015). Specifically, our analysis is based on the classification for the year 2007, which shows the best fit with our overall observation period. Labor market regions are more fine-grained than German planning regions (Raumordnungsregionen) or even NUTS2 regions and are therefore better suited for mapping the regional evolution of the German academic system. They aggregate several districts (Landkreise \& kreisfreie Städte; NUTS3) primarily on the basis of commuter flows; creating in most cases regions that contain a large city-which is often also a university location-and its surroundings. While labor market regions delineate functional regions in terms of local labor markets, due to the aggregation of administrative districts data from official statistics is available at this level of analysis. In addition, spillover effects across regions are much less of a concern at the level of labor market regions than they would be at the NUTS3 level. For a discussion of factors determining differences in labor market classifications see Binder and Schwengler (2006). For a discussion of the advantages and disadvantages of this classification, see, e.g., Eckey et al. (2007).

Even though funding is provided on the university level, we adopt regions as the unit of analysis. The main reason for this is that we are interested in how the shift toward academic excellence in German science policy affected the regional distribution and disparity of research activities. In some regions this means that 
quite different universities are considered together. However, in most cases a single university dominates all our data. In the remaining cases there has often been a discussion about a merger of the universities, the universities have been merged or the profiles have been adapted. Hence, we believe that the regional level is adequate for the analysis. Needless to say, there are numerous other questions for which a university-level analysis would be preferable, but these are not in the focus of the present paper.

\subsection{Data sources}

Different data sources are combined in our empirical analysis. Information about universities' institutional as well as third-party (or program) funding, as well as the number of students and professors, was obtained from official statistics on higher education collected by the German Statistical Office (Destatis). Specifically we use data from Fachserie 11, Reihe 4.3.2 "Bildung und Kultur". ${ }^{6}$ Employment data are obtained from official employment statistics (also Destatis). Patent data are taken from the European Patent Office's PATSTAT database (version April 2016) and allocated to labor market regions according to inventor addresses. Information about publications was collected from Web of Science (SCI and SSCI), fractionalized and regionalized by author address. All information was aggregated on the level of labor market regions.

The econometric analysis covers the 1999-2012 period. This allows us to study whether the influence of the explanatory variables changed after the policy shift toward competitive merit-based funding. As funding data (but not information on all other variables) is available throughout 2014, descriptive patterns of concentration (Gini coefficient) are reported for the 1998-2014 period. Our principal interest is in how the regional concentration of merit-based DFG funding changed over time. In addition, we also investigate developments in funding from other sources to have a standard of comparison for these changes. Funding from the Exzellenzinitiative is part of the DFG funds reported for the respective universities in the post-2005 years.

The German university system is not distributed equally across regions. A number of labor market regions have no or only very small universities (often universities of applied sciences lacking substantial levels of DFG funding). To focus attention on regions that play relevant roles in the competition for third-party funds, we restrict our empirical analysis to those 69 labor market regions that received more

\footnotetext{
6 Minor changes in the reporting system limit the usefulness of the data for longitudinal analysis. Before 2005, funds from "Hochschulfördergesellschaften" were not reported separately. However, this is of limited concern, as "Hochschulfördergesellschaften" only accounted for $1 \%$ of overall third party funding in 2012. In our analysis $50 \%$ of the funding by "Hochschulfördergesellschaften" is included in DFG funding. To control for sensitivity of the estimates we alternatively included $100 \%$ or $0 \%$, which did not change main results. For some universities public statistics do not contain data about universities' institutional as well third party funding for all locations for all years. This is only a concern for those regions where universities have locations in different labor market regions. This influences especially the regions Duisburg, Essen, Koblenz, Landau, Erlangen and Nuernberg. For these cases, funding is located proportional to the number of employees of the relevant university in the region. To check whether these locations influence our main results, we excluded these regions from our estimation, which does not influence our main results.
} 
than $€ 500,000$ in DFG funding for at least one year in the $1999-2012$ period. $^{7}$ This excludes all regions with no higher education institutions as well as all regions where only very small universities or universities of applied sciences are located. ${ }^{8}$ Because of structural differences in the remainder of the university system, university medical centers are also excluded 9 .

\subsection{Variables}

Regarding the characteristics of regions that are likely to benefit or suffer from a shift towards merit-based research funding, we utilize the following main explanatory variables. The aggregate size of the individual regions' universities is measured by the amount of institutional funding (laufende Grundmittel) aggregated across all universities located in the respective region (variable BasicFunding). University regions with traditional universities are indicated by a dummy variable taking the value 1 if at least one university in the region was founded before 1945 (Tradition). The overall number of employees is used as our measure of regional size (RegEmployment). We opted for an employment-based measure (instead of full population size) since it provides a better measure of the size of the regional economy, which we expect to be of primary relevance for our analysis.

In line with most work on innovation, regional patent shares are used to measure private-sector R\&D activities (RegPatents). ${ }^{10}$ All patents contained in the PATSTAT (April 2016) patent database are utilized to calculate these shares; they are assigned to labor market regions on the basis of inventor addresses. Our primary measure of regional non-university research activities is the number of regional employees in science, engineering, medical research, and agricultural research (RegResearchSTEM). ${ }^{11} \mathrm{~A}$ shortcoming of this variable is that besides PROs it also includes privatesector firms specialized in R\&D activities (but not R\&D intensive manufacturing firms). However, given the size of the German PRO sector, public research activities are expected to account for most of the variation in this variable. This is also in line with the official definition of the measure, which explicitly refers to the large PROs in Germany.

\footnotetext{
7 This is in line with previous investigations concerning allocation of DFG funding. For example, investigations in the DFG-Förderatlas are usually restricted to those universities that received more than two Mio. $€$ funding in the reporting period or the 20 (40) universities with the highest amount of funding. For a first basic analysis, Blume and Postlep (2009) restrict their investigation to those regions with regional universities that received more than 0.5 Mio. $€$ DFG funding in the reporting period.

${ }^{8}$ For example, the Theologische Fakultät Fulda, which has the right to confer doctoral degrees and habilitations, only had 11 professors in 2012.

9 The classification of some higher education institutions has changed in the time period under investigation. To avoid artificial variation our variables contain data from universities as well as universities of applied sciences for the respective regions included in our analysis.

10 The private sector dominates patenting activities in Germany.

11 Here we use industry class (NACE Rev. 1.1) "Research and experimental development on natural sciences and engineering". We also experimented with class "Research and experimental development on social sciences and humanities", but this turned out to be non-predictive and is not included in the results reported below.
} 
We control for the academic specialization of the university region, which is proxied by the share of students in science, technology, engineering and mathematics (STEM) programs among all students enrolled at the regional universities (ShareStudentsSTEM), as well as for research output using the number of regional Web of Science (SCI and SSCI) publications by professor (PubProf). We are aware of the restrictive nature of publications as a measure of research output. Most importantly for our purposes, due to discipline-specific differences in publication behavior, the journal-based publication variable does not equally measure research activities

Table 1 Description of Variables

\begin{tabular}{lll}
\hline Variable & Definition & Source \\
\hline DFG & Dep. variable, continuous, regional amount of third party & Destatis \\
& funding provided by DFG, inflation-adjusted in year 2005 & \\
& Euros. Contains 50\% of the funding by "Hochschulförderge- & \\
& sellschaften", log transformed &
\end{tabular}

Bund

Dep. variable, continuous, regional amount of third party

Destatis funding provided by federal ministries, inflation-adjusted in year 2005 Euros, log transformed

Private Funds Dep. variable, continuous, regional amount of third party

Destatis funding provided by private sector, inflation-adjusted in year 2005 Euros. Contains $50 \%$ of the funding by "Hochschulfördergesellschaften", log transformed

Internat

BasicFunding

StudentShareSTEM

PubProf

Tradition

RegEmployment

RegPatents

RegResearchSTEM

Excellence
Dep. variable, continuous, regional amount of third party funding provided by the European Union and other International Organizations, inflation-adjusted in year 2005 Euros, $\log$ transformed

Continuous, regional amount of university basic funding (Laufende Grundmittel), inflation-adjusted in year 2005 Euros, $\log$ transformed

Continuous, share of students in science, technology, engineering and mathematics (STEM) programs among all students enrolled at the regional university system, log transformed

Continuous, number of regional Web of Science publications (SCI and SSCI) regionalized and fractionalized by author address divided by the number of professors in the region, log transformed

Binary, value one if at least one university in the region was founded before 1945

Continuous, regional number of employees, log transformed

Continuous, regional patent shares estimated by all patents in region $i$ in year $t$ divided by all patents in Germany in year $t$ (contain all patents contained in the patent database PATSTAT (April 2016) of the European Patent Office) regionalized based on inventor addresses, log transformed

Continuous, the number of regional employees in companies in science, engineering, medical research and agricultural research (NACE Rev. 1.1: "Research and experimental development on natural sciences and engineering"), log transformed Binary, value 1 in all years after 2005
Destatis

Destatis

Destatis

Web of

Science

Own Research

Destatis

PATSTAT

Destatis

Own Calculation 
Table 2 Summary Statistics

\begin{tabular}{llllll}
\hline Variables & $(1)$ & $(2)$ & $(3)$ & $(4)$ & $(5)$ \\
& $N$ & Mean & sd & Min & Max \\
\hline DFG & 897 & 15.95 & 1.328 & 11.97 & 18.74 \\
PrivateFunds & 897 & 15.18 & 2.431 & 0 & 18.43 \\
Bund & 897 & 15.49 & 1.579 & 0 & 18.38 \\
Internat & 894 & 14.49 & 1.783 & 0 & 17.69 \\
BasicFunding & 897 & 18.85 & 0.828 & 16.25 & 20.91 \\
PubProf & 897 & -0.0454 & 1.162 & -6.716 & 1.743 \\
StudentShareSTEM & 897 & -0.993 & 0.819 & -6.908 & 0.001000 \\
Tradition & 897 & 0.725 & 0.447 & 0 & 1 \\
RegEmployment & 897 & 12.00 & 0.796 & 10.29 & 13.95 \\
RegPatents & 897 & -5.086 & 0.957 & -6.684 & -2.310 \\
RegResearchSTEM & 897 & 6.361 & 1.757 & 0 & 9.809 \\
\hline
\end{tabular}

across disciplines. Even though this bias is partially counteracted by controlling for the regional STEM specialization and the presence of traditional universities, it nonetheless needs to be considered in the interpretation of results. Table 1 gives an overview of all variables used in the model. Descriptive statistics and pairwise correlations between the variables are provided in Table 2 and 3.

\subsection{Methods}

We begin our empirical analysis by examining changes in the regional concentration of DFG funding using Gini coefficients as the measure of statistical dispersion. We also show changes in concentration relative to the base year 1998, which allows us to compare the degree of inequality in the periods before and after the change to merit-based research funding.

To probe into the factors that are associated with the observable changes in the regional concentration of funding, we then turn to an econometric analysis. Specifically, we regress the DFG funding of region $i$ in period $t$ on the set of regional characteristics outlined above. All variables (except Tradition) are log-transformed for the econometric analysis. Due to log-log transformation of the dependent and independent variables, our estimates can easily be interpreted as elasticities. All monetary variables are inflation-adjusted in year 2005 Euros. The general specification is a pooled OLS model for the 69 regions and 13 periods of observation given by Eq. 1:

$$
\begin{aligned}
\log \left(\mathrm{DFG}_{i t}\right) & =\alpha+\beta \log \left(X_{i t-1}\right)+\gamma \log \left(X_{i t-1}\right) * \text { Excellence }+\delta \log \left(Z_{i t-1}\right) \\
& +\sum_{t} \varepsilon_{t} \text { Year }_{t}+\sum_{s} \varepsilon_{s} \text { State }_{s}+u_{i t}
\end{aligned}
$$

In this specification, $X_{\mathrm{it}-1}$ is a vector of explanatory variables and $Z_{\mathrm{it}-1}$ is a vector of controls. Effects of a shift toward more competitive merit-based funding during the time period under investigation are identified through $X_{\mathrm{it}-1}$ *Excellence, 


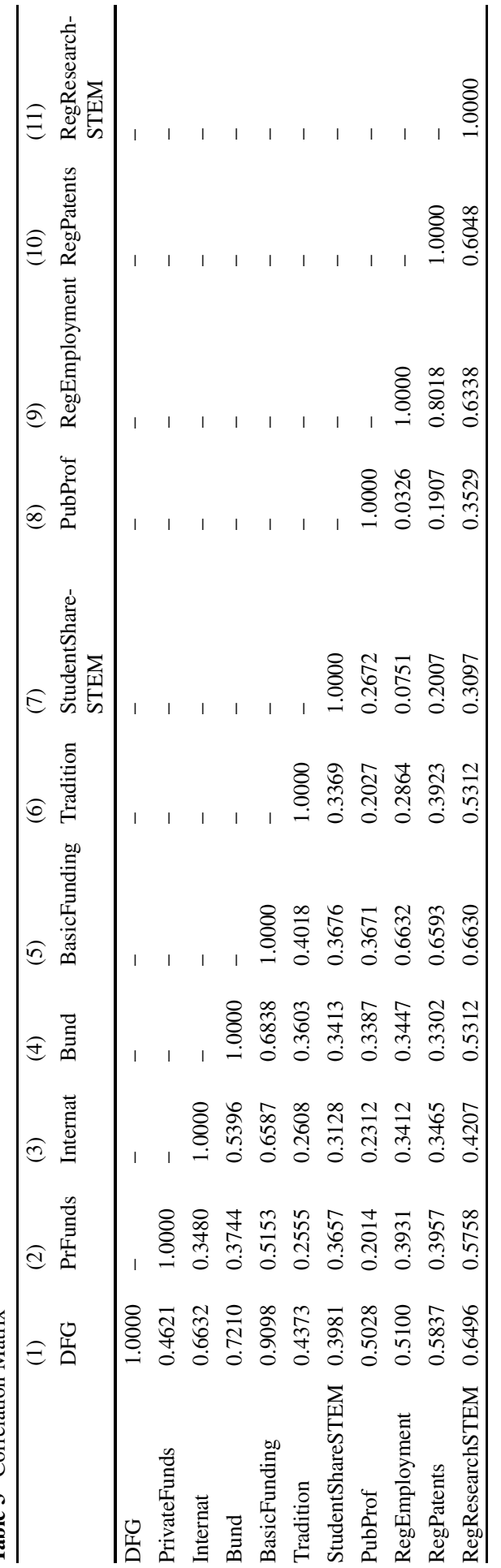



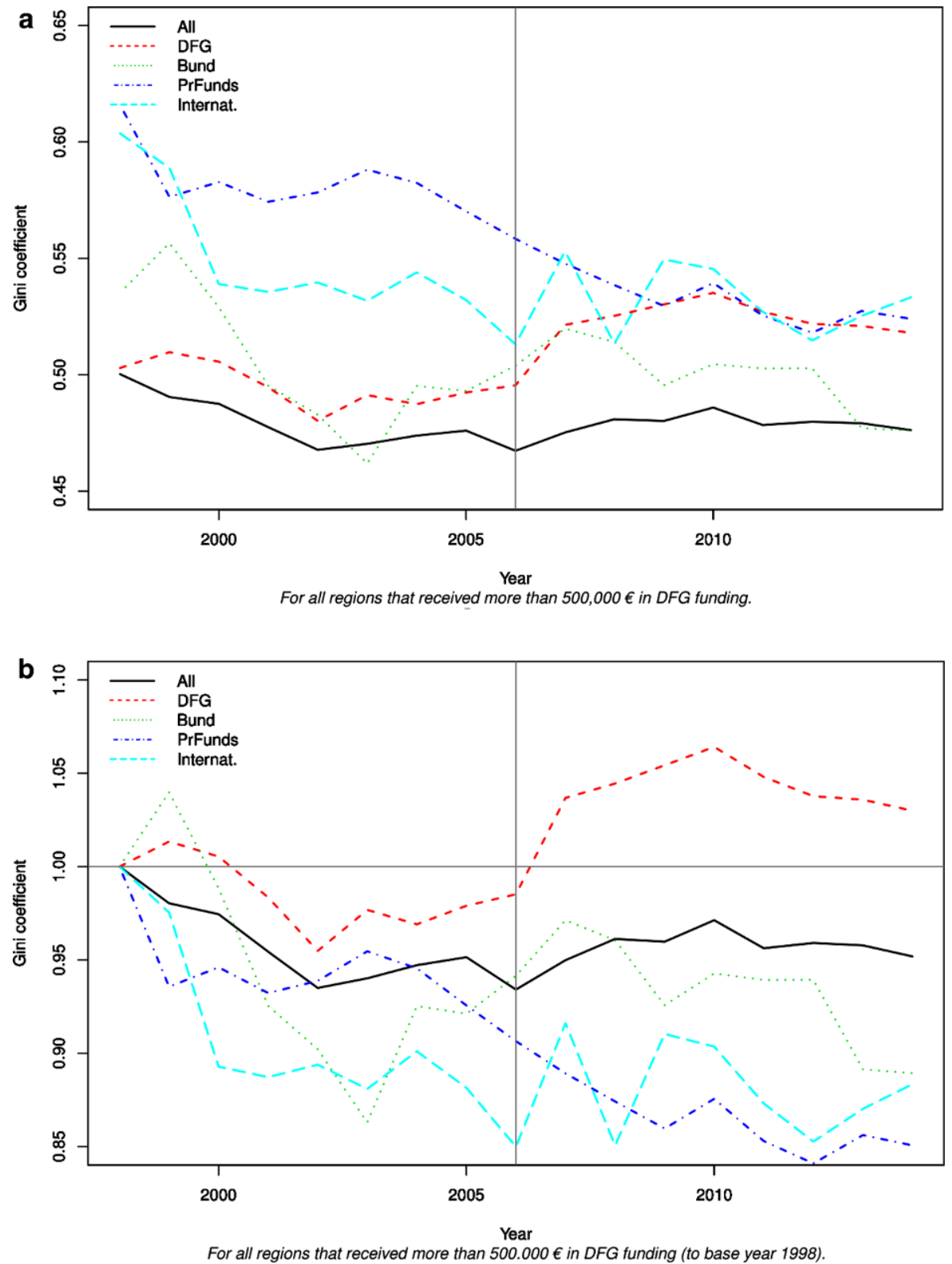

Fig. 1 Regional concentration (1998-2014). a Gini coefficient, b relative change of Gini coefficient 
i. e. interaction terms between our main explanatory variables and a dummy taking value 1 in all years after 2005, the year when the Exzellenzinitiative was passed by the German federal and state governments (Excellence). ${ }^{12}$

All explanatory variables and controls are lagged by one period, taking into account that the average processing time for individual grants is about six months (DFG 2016). ${ }^{13}$ Year dummies control for time-fixed effects in all specifications. State (Länder) dummies are included to control for the fact that the federal states have legislative power over large parts of the higher educational system in Germany. Standard errors are corrected for serial correlation by clustering on regions.

We also estimated models incorporating a full set of fixed effects for the individual labor market regions, thus controlling for time-invariant unobserved heterogeneity across regions (fixed effects panel regression). However, the coefficients obtained in fixed effects models are driven by longitudinal variation in the variables, some of which vary little over time. Accordingly, we decided against focusing on the fixed effects specification but rather consider it as providing additional evidence in the spirit of a robustness check.

\section{Results}

\subsection{Descriptive patterns}

Fig. 1 shows the development of concentration in third party funding from various sources among the 69 observed university regions, measured by the Gini coefficient. On the whole, regional inequality tended to decline after 1998, with DFG funds being the only type of funding for which concentration has increased. The figure also shows that the concentration of DFG funding was quite stable before 2006. However, it increased rapidly after the shift towards more competitive merit-based funding (from 0.492 in 2005 to 0.535 in 2010). Since 2010, the regional concentration of DFG funding has declined again, but in 2014 it was still about $3 \%$ higher than in 1998. This indicates that a new steady state — at a higher level of concentration-has been reached.

Fig. 2 plots the regional distribution of DFG funds in the years 1999, 2005 and 2012 for the 69 observed regions. Munich and Berlin are the labor market regions with the highest amounts of merit-based funding in all years. Both regions are home to several universities that moreover tended to be quite successful in the Exzellenzinitiative. DFG funding is moreover concentrated in Western and Southwestern Germany. The inflation-adjusted mean and median of DFG funding increased substantially in the time period under observation (median: from 9.2 million $€$ in 2005 to 18.2 million $€$ in 2012). This shows that, despite the increasing regional concentration, average universities received higher absolute levels of merit-based funding after the policy shift.

\footnotetext{
12 The primary effect of Excellence is absorbed in the Year dummies.

13 Moreover, the Bayesian Information Criterion (Schwarz 1978) indicated an optimal leg length of one year.
} 


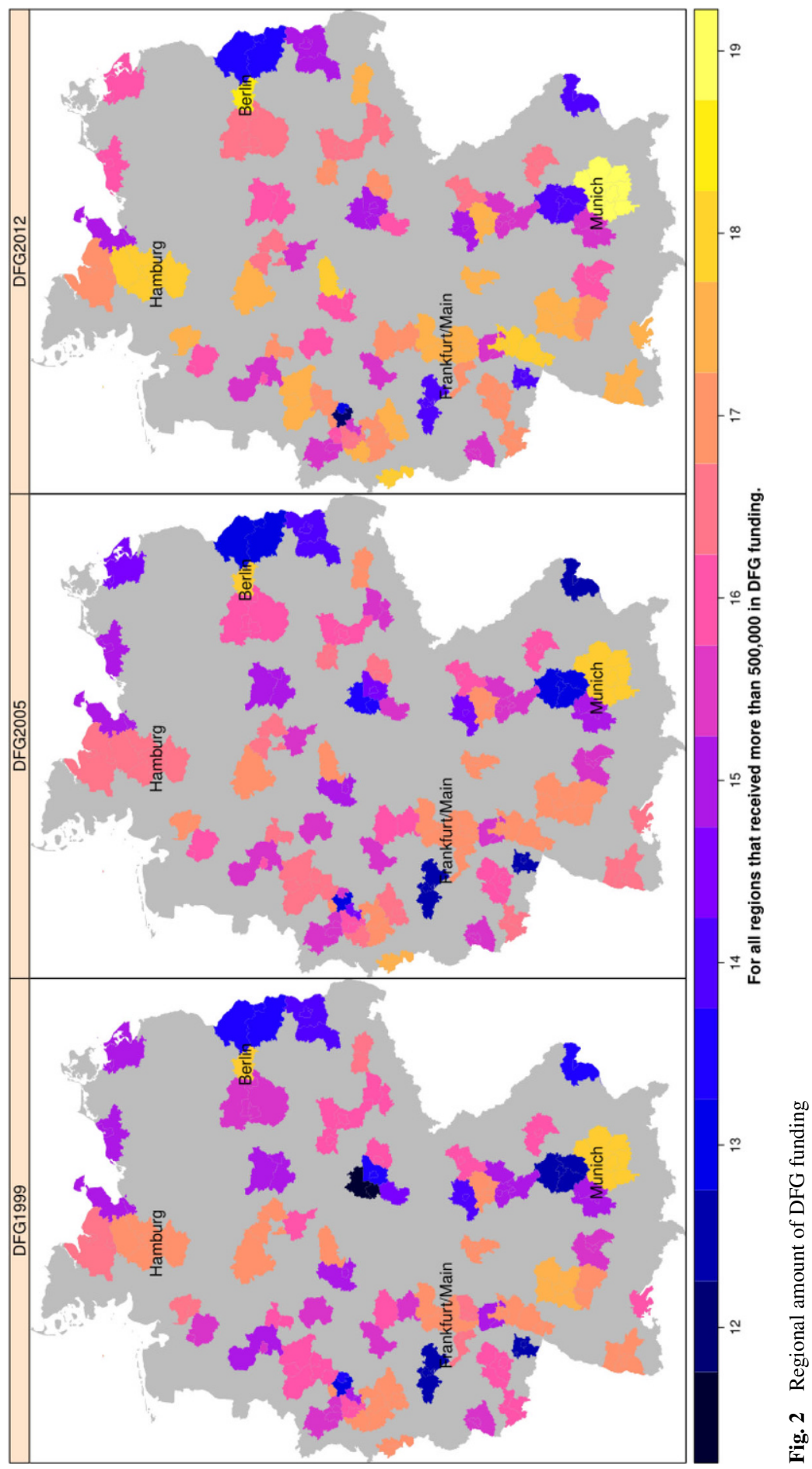




\subsection{Econometric findings}

We now turn to the econometric analysis of regional factors associated with the concentration of research funding and its changes after 2005. Our baseline specification (Model 1 in Table 4) shows that the amount of DFG funding allocated to a university region increases with the aggregate university size in the region, with the elasticity significantly above one. In other words, regions with larger aggregate university size seem to benefit more than proportionately from merit-based research funding. The

Table 4 Determinants of Merit-Based Research Funding

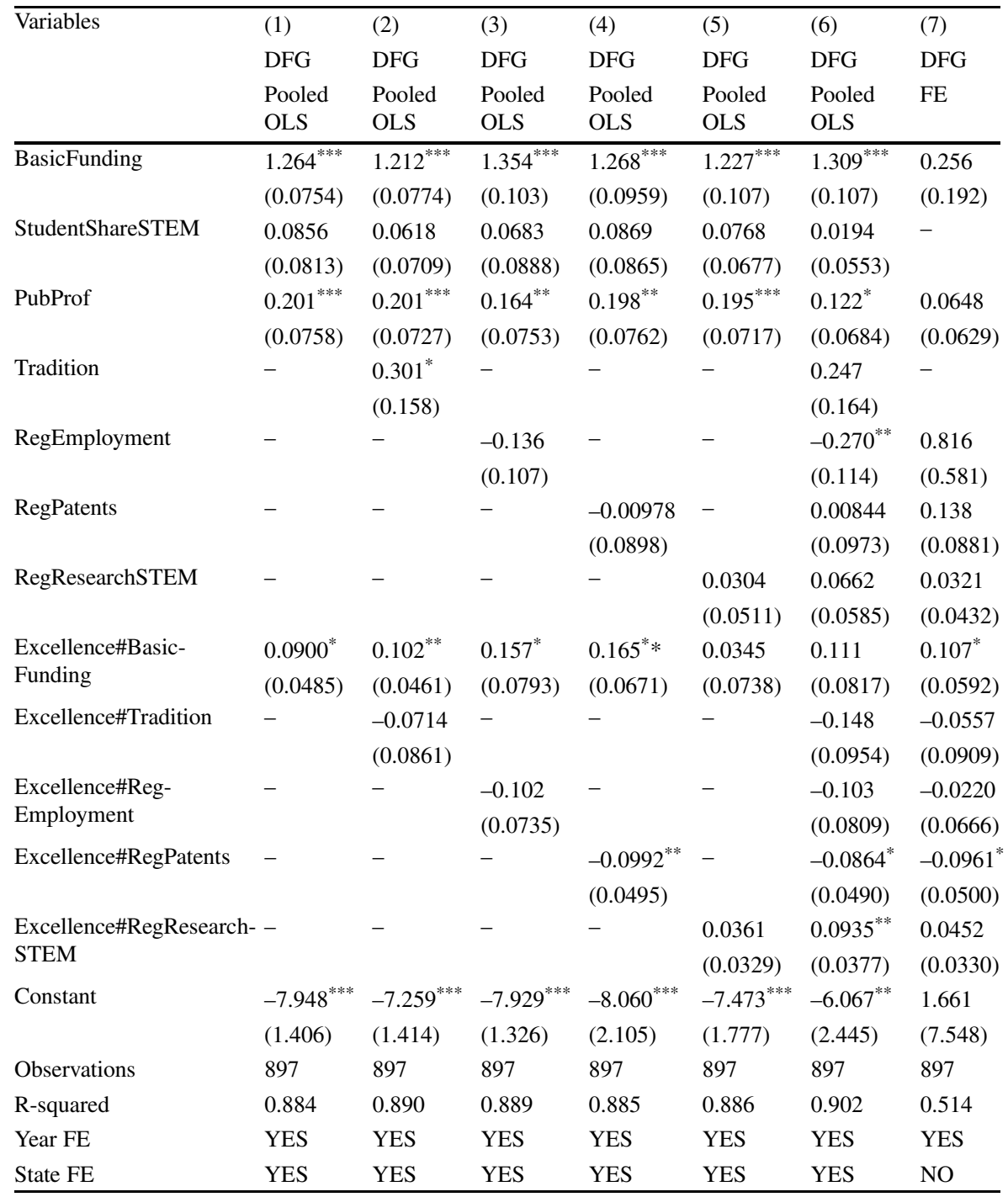

Robust standarderrors in parentheses

${ }^{* * * *} p<0.01,{ }^{* *} p<0.05,{ }^{*} p<0.1$ 
point estimate implies that a $1 \%$ increase in size is associated with a $1.26 \%$ increase in DFG funding. ${ }^{14}$ We moreover estimate a positive and marginally significant (at the 0.1 level) coefficient for the interaction term, indicating that the advantage of larger university regions got more pronounced after 2005. This is consistent with the prediction of Hypothesis 1. Not surprisingly, we also obtain a significant positive association between DFG funds and publication output per professor. In contrast, the measure of STEM specialization is not predictive.

In models $2-5$ we individually include further explanatory variables, as well as their interactions with the dummy denoting post-Exzellenzinitiative years in the model specification. Model 6 includes the full set of explanatory variables. Given substantial pair-wise correlations between the explanatory variables (cf. Table 3), this approach appears more conservative than only reporting results from the full specification. ${ }^{15}$ As regards our main result from Model 1-regions with larger aggregate university size benefitting more from the shift toward competitive merit-based funding - the evidence from models $2-6$ is mixed. In models $2-4$, the coefficient estimated for the interaction term becomes both more sizeable and more strongly significant. However, it loses significance when regional public research activities are taken into consideration (model 5) or when all explanatory variables are included (model 6).

Regarding the other hypotheses, model 2 finds a positive and marginally significant association between being a traditional university region and the level of DFG funding. However, counter to Hypothesis 2 our results do not suggest that this association became stronger after 2005. Model 3 includes overall employment in the region. Neither does it suggest that universities in larger regions are better positioned to obtain DFG funding. Nor do we find evidence of a systematic change in the role of regional size after 2005, as was posited in Hypothesis 3. Model 4 suggests that universities in regions with stronger private-sector R\&D activities actually captured a smaller share of DFG funds after 2005. Accordingly, no support for Hypothesis 4 is obtained in this model, but the marginally significant negative coefficient even suggests that universities located in more innovative regions may have received less merit-based funding after the Exzellenzinitiative was introduced. We also find no support for Hypothesis 5 tested in model 5, which includes regional STEM research employment, our proxy for the size of regional PRO activities. Note, however, that this variable becomes significant for the post-2005 years in model 6 including all explanatory variables. Other than that and except for the now significantly negative primary effect of regional employment, model 6 does not change our earlier findings. In particular, the interaction terms with the other explanatory variables are very similar to those of models $2-5$ in terms of signs and significance. Model 7 is a fixed-effects variant of model 6 (without the primary effects of Tradition and StudentShareSTEM, which show no or very little variation over time and are therefore

\footnotetext{
14 Unreported model variants including a quadratic term indicate that the size advantage get less strong as university size increases. However, its implied maximum is reached at values far exceeding observable sizes.

15 Note, however, that variance inflation factors (estimated for models without interaction terms) are below the critical threshold of 10 , which does not suggest that collinearity is a substantial concern.
} 
excluded $\left.{ }^{16}\right)$. In the fixed-effects setup, none of the primary effects of the variables retains its significance. As regards our hypotheses about potential repercussions of the shift toward more merit-based funding, which are reflected in the interaction terms, results are similar to model 6 . However, in line with model 5, the interaction term for regional STEM research employment is no longer significant in the fixed-

Table 5 Results for other Funding Sources

\begin{tabular}{|c|c|c|c|}
\hline \multirow[t]{3}{*}{ Variables } & (1) & (2) & (3) \\
\hline & Bund & PrFunds & Internat \\
\hline & Pooled OLS & Pooled OLS & Pooled OLS \\
\hline \multirow[t]{2}{*}{ BasicFunding } & $1.246^{* * *}$ & 0.365 & $1.687^{* * *}$ \\
\hline & $(0.117)$ & $(0.424)$ & $(0.291)$ \\
\hline \multirow[t]{2}{*}{ StudentShareSTEM } & $0.173^{*}$ & $0.589^{* *}$ & 0.148 \\
\hline & $(0.0884)$ & $(0.260)$ & $(0.110)$ \\
\hline \multirow[t]{2}{*}{ PubProf } & 0.0589 & -0.249 & -0.123 \\
\hline & $(0.0887)$ & $(0.171)$ & $(0.0948)$ \\
\hline \multirow[t]{2}{*}{ Tradition } & -0.0876 & -0.976 & 0.283 \\
\hline & $(0.194)$ & $(1.064)$ & $(0.306)$ \\
\hline \multirow[t]{2}{*}{ RegEmployment } & -0.171 & -0.640 & $-0.439^{*}$ \\
\hline & $(0.164)$ & $(0.460)$ & $(0.225)$ \\
\hline \multirow[t]{2}{*}{ RegPatents } & -0.0761 & $0.966^{* *}$ & -0.0696 \\
\hline & $(0.144)$ & $(0.455)$ & $(0.220)$ \\
\hline \multirow[t]{2}{*}{ RegResearchSTEM } & 0.0317 & $0.679^{* *}$ & 0.0154 \\
\hline & $(0.0827)$ & $(0.339)$ & $(0.0729)$ \\
\hline \multirow[t]{2}{*}{ Excellence\#BasicFunding } & 0.240 & 0.457 & -0.0154 \\
\hline & $(0.295)$ & $(0.355)$ & $(0.379)$ \\
\hline \multirow[t]{2}{*}{ Excellence\#Tradition } & $0.493^{*}$ & 0.454 & -0.431 \\
\hline & $(0.290)$ & $(0.665)$ & $(0.284)$ \\
\hline \multirow[t]{2}{*}{ Excellence\#RegEmployment } & -0.152 & -0.0621 & 0.230 \\
\hline & $(0.169)$ & $(0.285)$ & $(0.171)$ \\
\hline \multirow[t]{2}{*}{ Excellence\#RegPatents } & -0.235 & -0.0967 & -0.274 \\
\hline & $(0.221)$ & $(0.160)$ & $(0.207)$ \\
\hline \multirow[t]{2}{*}{ Excellence\#RegResearchSTEM } & 0.121 & -0.395 & 0.00843 \\
\hline & $(0.109)$ & $(0.349)$ & $(0.0881)$ \\
\hline \multirow[t]{2}{*}{ Constant } & $-6.181^{*}$ & $17.60^{*}$ & $-12.40^{* *}$ \\
\hline & (3.118) & $(10.08)$ & $(5.923)$ \\
\hline Observations & 897 & 897 & 894 \\
\hline R-squared & 0.594 & 0.484 & 0.508 \\
\hline Year FE & YES & YES & YES \\
\hline State FE & YES & YES & YES \\
\hline
\end{tabular}

Robust standarderrors in parentheses ${ }^{* * * *} p<0.01,{ }^{* *} p<0.05,{ }^{*} p<0.1$

16 DFG (2015) suggests that the concentration of DFG funds on the subject level remained stable over time. 
effects setup. Overall, our model explains a large share of variation in the dependent variable. Unreported simulations (available from the authors upon request) show that it is able to reproduce the post-2005 increase in concentration.

Table 5 reports results from corresponding analyses for the other three major funding sources in Germany (Bund, i. e. the federal ministries; private funders, as well as international sources). In contrast to the DFG funds analyzed above, there is no evidence whatsoever that the importance of characteristics of universities or regions changed after 2005 for the three alternative sources. Only the interaction term for Tradition in the Bund specification became marginally significant (at the 0.1 level). Apparently, the regime shift in DFG funding (including the Exzellenzinitiative) has so far not spilled over to other funding types. Federal ministries, moreover, tend to favor larger university regions and those with a STEM orientation. Not surprisingly, private funding is biased towards the STEM fields. Private funding is also significantly larger in regions with stronger private-sector R\&D as well as non-university public research activities.

Summing up, we find an increase in regional inequality with the shift toward merit-based funding. This result is in line with prior descriptive findings on the level of universities (DFG 2012). In contrast, we find very limited support for our hypotheses regarding winning and losing regions. Size effects are observable from the outset (consistent with Auspurg et al. 2008). We also obtain some evidence suggesting that, in line with the prediction of Hypothesis 1, the advantage of larger university regions increased after the Exzellenzinitiative was introduced. However, the significance of the corresponding estimates varied across the models, so at this time we are cautious in interpreting them. Our results do not support Hypothesis 2 or the corresponding conjectures by Münch (2006), as well as Blume and Postlep (2009), positing that regions with a long university history will be in an advantageous position. Nor do we find support for Hypotheses 3 and 4 about the roles of regional size and private-sector R\&D, respectively. Finally, regarding importance of nonuniversity public research, which was the subject of Hypothesis 5, only one out of three models finds a significant increase after 2005.

\section{Concluding remarks}

Substantial controversy surrounds the policy regime shift toward a focus on research "excellence" that recently took place in Germany. So far this debate has not paid much attention to potential repercussions at the regional level. This is surprising because it is plausible to expect that the focus on excellence may favor regions that already are more prosperous and innovative than others. Given the importance of universities to regional economic development, the shift toward excellence might then come at the cost of increasing regional disparity.

In this paper, we began to trace the evolution of regional concentration in meritbased university research funding after the policy shift, as well as factors that help account for the regions that are among the winners and losers of this shift. To the best of our knowledge, this question has not been addressed in a multivariate framework before. We found that the regional concentration of merit-based public funding of 
university research has increased since the mid-2000s. At the same time the inflation adjusted median amount of DFG-funding substantially increased. However, except for some evidence suggesting benefits to regions with larger overall university size, our theory-based predictions about factors likely to explain this increase were not borne out by the empirical analysis. Contrary to our predictions, our results even point to the possibility that universities in innovative regions may have become less likely to receive DFG funding after the shift. Although this evidence has to be interpreted with caution (see above), it might indicate that DFG funding contributes to an increasing mismatch between private innovation activities in the regional economy and university research through increasing university research especially in economically less innovative regions.

In this paper we could only provide a first attempt at probing into these issues, and our analysis suffers from limited data availability. In particular, we have not been able to replicate the analysis on the more disaggregated level of individual fields and disciplines. It is also too early to tell whether mutually reinforcing coevolutionary processes of regional research and innovation performance amplify the differences across the individual regions. To fully understand what the shift toward "excellence" did to the regional effects of universities, substantial further research effort is required. Yet given the importance of university research for innovation and economic development, this effort would clearly be worthwhile.

Open Access This article is distributed under the terms of the Creative Commons Attribution 4.0 International License (http://creativecommons.org/licenses/by/4.0/), which permits unrestricted use, distribution, and reproduction in any medium, provided you give appropriate credit to the original author(s) and the source, provide a link to the Creative Commons license, and indicate if changes were made.

\section{References}

Arzt C et al (2016) Für gute Forschung und Lehre - Argumente gegen die Exzellenzinitiative. mimeo

Astebro T, Bazzazian N (2011) Universities, Entrepreneurship and Local Economic Development. In: Fritsch M (ed) Handbook of Research on Entrepreneurship and Regional Development. Edward Elgar, Cheltenham

Auspurg K, Hinz T, Güdler J (2008) Herausbildung einer akademischen Elite? Kolner Z Soz Sozpsychol 60(4):653-685

Azoulay P, Ding W, Stuart T (2009) The impact of academic patenting on the rate, quality and direction of (public) research output. J Ind Econ 57(4):637-676

Beckenbach F, Daskalakis M, Hofmann D (2011) Die ökonomische Bedeutung der Universität Kassel für die Region Nordhessen. In: Universität Kassel (ed) 40 Jahre Universität Kassel, pp 22-25

Belenzon S, Schankerman M (2013) Spreading the word: Geography, policy, and knowledge spillovers. Rev Econ Stat 95(3):884-903

Binder J, Schwengler B (2006) Neuer Gebietszuschnitt der Arbeitsmarktregionen im Raum Berlin und Brandenburg. Kritische Überprüfung der bisher gültigen Arbeitsmarktregionen und Vorschläge für einen Neuzuschnitt. IAB-Forschungsbericht, vol. 4.

Blankenberg AK, Buenstorf G (2016) Regional co-evolution of firm population, innovation and public research? Evidence from the West German laser industry. Res Policy 45(4):857-868

Blume L, Postlep RD (2009) Veränderungen der Hochschulfinanzierung aus regionalpolitischer Sicht. In: Mäding H (ed) Öffentliche Finanzströme und räumliche Entwicklung. Forschungs- und Sitzungsberichte der ARL, vol 232. Verlag der ARL, Hannover, pp 135-146

Brenner T, Duschl M (2015) Causal dynamic effects in regional systems of technological activities: a SVAR approach. Ann Reg Sci 55(1):103-130

Buenstorf G, Geissler M, Krabel S (2016) Locations of labor market entry by German university graduates: is (regional) beauty in the eye of the beholder? Rev Reg Res 36(1):29-49 
Deutsche Forschungsgemeinschaft (2012) Förderatlas 2012 - Kennzahlen zur öffentlich finanzierten Forschung in Deutschland. DFG (Deutsche Forschungsgemeinschaft), Bonn

Deutsche Forschungsgemeinschaft (2015) Förderatlas 2015 - Kennzahlen zur öffentlich finanzierten Forschung in Deutschland. DFG (Deutsche Forschungsgemeinschaft), Bonn

DFG (Deutsche Forschungsgemeinschaft) (2006) Förder-Ranking 2006 - Institutionen - Regionen - Netzwerke. DFG (Deutsche Forschungsgemeinschaft), Bonn

DFG (Deutsche Forschungsgemeinschaft) (2016) FAQ: Temporary Positions for Principal Investigators. http://dfg.de/en/research_funding/faq/faq_temporary_positions/index.html. Accessed 9 May 2016

Dohse D (2007) Cluster-Based Technology Policy-The German Experience. Ind Innov 14(1):69-94

Drucker J, Goldstein H (2007) Assessing the regional economic development impacts of universities: A review of current approaches. Int Reg Sci Rev 30:20-46

Eckey HF, Schwengler B, Türck M (2007) Vergleich von deutschen Arbeitsmarktregionen. IAB Discussion Paper, vol. 3.

Eickelpasch A, Fritsch M (2005) Contests for cooperation-A new approach in German innovation policy. Reg Policy 34(8):1269-1282

Ellwein T (1985) Die deutsche Universität: vom Mittelalter bis zur Gegenwart. Athenäum, Königstein/ Taunus

Etzkowitz H, Leydesdorff L (2000) The dynamics of innovation: from National Systems and "Mode 2" to a Triple Helix of university-industry-government relations. Res Policy 29(2):109-123

Faggian A, Cann MP (2009) Human capital, graduate migration and innovation in British regions. Cambridge J Econ 33(2):317-333

Fritsch M, Slavtchev V (2007) Universities and Innovation Space. Ind Innov 14(2):201-218

Fritsch M, Henning T, Slavtchev V, Steigenberger N (2007) Hochschulen. Innovation, Region: Wissenstransfer im räumlichen Kontext. Edition Sigma, Berlin

Hartmann M (2010) Die Exzellenzinitiative und ihre Folgen. Leviathan 38(3):369-387

Hüther O, Krücken G (2016) Fragestellungen, Ergebnisse und Perspektiven der sozialwissenschaftlichen Hochschulforschung. Springer, Berlin

Imboden D, Lütjen-Drecoll E, Bargmann S, Casper G, Gächter S, Kratky C, Nahrstedt K, Bech Nosch ML, Pauss F, Scheidegger D (2016) Internationale Expertenkommission zur Evaluation der Exzellenzinitiative - Endbericht

Jacobs J (1961) The Death and Life of Great American Cities. Vintage Books, New York

Jaffe A (1989) Real Effects of Academic Research. Am Econ Rev 79(5):957-970

Kehm B (2006) The German "Initiative for Excellence" and the Issue of Ranking. Int High Educ 44:20-22

Mayntz R (1994) Deutsche Forschung im Einigungsprozess: die Transformation der Akademie der Wissenschaften der DDR 1989 bis 1992. Campus, Frankfurt/Main

Münch R (2006) Wissenschaft im Schatten von Kartell, Monopol und Oligarchie. Die latenten Effekte der Exzellenzinitiative. Leviathan 34(4):466-486

Perkmann M, Tartari V, McKelvey M, Autio E, Broström A, D’Este P, Fini R, Geuna A, Grimaldi R, Hughes A, Krabel S, Kitson M, Llerena P, Lissoni F, Salter A, Sobrero M (2013) Academic engagement and commercialisation: A review of the literature on university-industry relations. Res Policy 42(2):423-442

Picht G (1964) Die deutsche Bildungskatastrophe: Analyse und Dokumentation. Walter, Olten

Potì B, Reale E (2007) Changing allocation models for public research funding: an empirical exploration based on project funding data. Sci Public Policy 34(6):417-430

Schneider M, Ji BM (1990) The political economy of intergovernmental grant seeking: Targeting and suburbs, 1977 and 1982. Am J Pol Sci 34(2):408-420

Schubert T, Kroll H (2014) Universities' effects on regional GDP and unemployment: The case of Germany. Pap Reg Sci. https://doi.org/10.1111/pirs.12150

Schwarz G (1978) Estimating the dimension of a model. Ann Stat 6:461-464

Statistisches Bundesamt (Destatis) (2013) Finanzen der Hochschulen, Fachserie 11, Reihe 4.5. Statistisches Bundesamt (Destatis), Wiesbaden

Statistisches Bundesamt (Destatis) (2016) Finanzen der Hochschulen, Fachserie 11, Reihe 4.5. Statistisches Bundesamt (Destatis), Wiesbaden

Stephan PE (2012) How Economics Shapes Science. Harvard University Press, Cambridge

Vogt G (2014) Der Druck wächst: Drittmittelfinanzierung der Hochschulen. Forsch Lehre 2:96-98

Winterhager N (2015) Drittmittelwettbewerb im universitären Forschungssektor. Springer VS, Wiesbaden 